DOI: http://dx.doi.org/10.12957/demetra.2015.14293

\title{
Valores nutricionais e qualitativos de carnes bovinas (Longissimus thoracis) provenientes de sistemas de produção orgânica e convencional
}

\section{Nutritional and qualitative values of bovine beef (Longissimus thoracis) from organic and conventional production systems}

\author{
Ana Paula Costa Rodrigues Ferraz' \\ Jessica Moraes Malheiros² \\ Renata Maria Galvão de Campos Cintra ${ }^{3}$ \\ Luis Artur Loyola Chardul $0^{4}$ \\ 1 Universidade Estadual Paulista "Júlio de \\ Mesquita Filho", Departamento de Química e \\ Bioquímica, Instituto de Biociências, Curso de \\ Nutrição. Botucatu-SP, Brasil. \\ 2 Universidade Estadual Paulista "Júlio de \\ Mesquita Filho", Departamento de Zootecnia, \\ Faculdade de Ciências Agrárias e Veterinárias, \\ Programa de Pós-Graduação em Genética e \\ Melhoramento Animal. Botucatu-SP, Brasil. \\ ${ }^{3}$ Universidade Estadual Paulista "Júlio de \\ Mesquita Filho", Departamento de Educação, \\ Instituto de Biociências. Botucatu-SP, Brasil. \\ ${ }^{4}$ Universidade Estadual Paulista "Júlio de \\ Mesquita Filho", Departamento de Nutrição e \\ Melhoramento Animal, Faculdade de Medicina \\ Veterinária e Zootecnia. Botucatu-SP, Brasil. \\ Correspondência / Corrrespondence \\ Jessica Moraes Malheiros \\ E-mail: jessicamalheiros@yahoo.com.br
}

\section{Resumo}

O objetivo deste estudo foi avaliar os efeitos da produção de animais sob o sistema de manejo orgânico e convencional em relação à qualidade da carne de bovinos machos Nelore (Bos indicus). Foram utilizados oito animais provenientes do sistema de produção orgânica e 15 animais produzidos sob o sistema convencional terminados em confinamento por 90 dias. Após o abate, as carcaças foram resfriadas no período de 24 a 48 horas, e duas amostras do músculo Longissimus thoracis foram coletadas com aproximadamente $2,54 \mathrm{~cm}$ de espessura entre a $12^{\mathrm{a}}-13^{\mathrm{a}}$ costelas da meia carcaça esquerda de cada bovino. Foram avaliadas características químicas, como lipídeos totais (LT) e índice de fragmentação miofibrilar (MFI). De modo suplementar, avaliaram-se características como força de cisalhamento (FC), área de olho de lombo (AOL), índice de marmorização (IM), espessura de gordura subcutânea (EGS), composição centesimal, perdas totais (PT) e coloração instrumental. Constatou-se que as amostras de procedência orgânica apresentaram melhores características de coloração instrumental, considerada o principal atrativo no momento da compra. $\mathrm{O}$ valor médio de força de cisalhamento foi menor para a carne orgânica, sendo positivamente relacionado com a maciez. Diferenças significativas entre os dois grupos também podem ser observadas nas análises de lipídeos totais, espessura de gordura e teor de umidade, que apresentaram valores superiores em relação aos animais terminados em confinamento.

Palavras-chave: Espessura de Gordura. Maciez. Qualidade da Carne, Umidade da Carne. 


\section{Abstract}

This study aimed to evaluate the effects of livestock production on organic and conventional management system in relation to meat quality of Nellore male cattle (Bos indicus). Eight animals under organic production system and 15 animals produced under conventional system finished in feedlot for 90 days were used. After slaughter, the carcasses were cooled within 24 to 48 hours and two samples of the Longissimus thoracis were collected with approximately $2.54 \mathrm{~cm}$ thick between the $12^{\text {th }}$ to $13^{\text {th }}$ ribs of the left half of each animal. Chemical characteristics were evaluated, such as total lipids (TL) and myofibrillar fragmentation index (MFI). Additional mode was evaluated for characteristics such as shear force (SF), rib eye area (REA), marbling index (IM), backfat thickness (BFT), centesimal composition, total losses (LT) and instrumental coloring. It was found that the organic origin of samples showed best features of instrumental color, considered the main attraction at the time of purchase. The average shear force was lower for organic meat and is positively related to softness. Significant differences between the two groups can also be observed in the total lipid analysis, fat thickness and moisture content, which showed higher values than animals finished in feedlot.

Key words: Backfat Thickness. Softness. Meat Quality. Moisture of the Meat.

\section{Introdução}

A alimentação saudável desperta crescente interesse dos consumidores, com relação ao consumo de alimentos orgânicos, considerados produtos benéficos, nutritivos e de menor risco à saúde, frente a grande comercialização de alimentos industrializados e menor valorização de alimentos tradicionais na dieta dos brasileiros. ${ }^{1}$

No Brasil, observa-se aumento significativo e constante na prática de produção orgânica, tendo sido registrado no ano de 2010 crescimento de $40 \%$ nas vendas, comparado a 2009, totalizando $\mathrm{R} \$ 350$ milhões de reais. Apresentando-se, assim, um grande potencial na conquista do mercado externo, devido principalmente à relação com a essência da agroecologia e a segurança alimentar. ${ }^{1-3}$

No setor da pecuária orgânica, a prevenção de doenças é eliminada progressivamente e o uso de medicamentos alopáticos (incluindo antibióticos) é reduzido. A alimentação 
dos animais ocorre com produtos de origem animal e mantêm-se a saúde e o bem-estar, demonstrados pelo abate de 13.800 cabeças/ano de bovinos orgânicos oriundos de 18 produtores certificados. Além disso, há o empenho da população em preservar o meio ambiente e a geração de produtividade e rentabilidade. ${ }^{4}$

O principal fator negativo de influência no mercado é o preço, geralmente elevado em comparação ao produto convencional, sendo considerado um dos maiores entraves para o desenvolvimento da produção orgânica no Brasil. ${ }^{5}$ Os quesitos mais observados pelo consumidor no momento da compra são coloração, gordura visível, preço e corte cárneo. ${ }^{6}$

Estima-se que a produção de carne bovina brasileira terá crescimento significativo, de $29 \%$ entre o ano 2013 e 2023, aumentando $20 \%$ da sua participação no mercado global. Já foram alcançados aproximadamente 27 milhões de abates no final de 2013 em relação aos 24 milhões de cabeças abatidas em 2012 - dentro desses parâmetros, o Brasil ocupa posição de destaque na produção de carne bovina., ${ }^{7,8}$

Os animais da raça Nelore e seus cruzados compõem o rebanho brasileiro, e torna-se imprescindível um sistema de produção que potencialize a maciez, considerada a principal característica organoléptica de qualidade da carne dentro do mercado consumidor. ${ }^{9}$ A cobertura de gordura adequada e um bom grau de marmorização também são componentes essenciais na qualidade da carne, influenciando de forma direta o grau de maciez e palatabilidade. ${ }^{10,11}$

Neste contexto, o trabalho teve como objetivos avaliar as influências diretas das variações dos sistemas de produção em relação à composição química da carne e qualidade do músculo Longissimus thoracis de bovinos Nelore, visando ao mercado consumidor e à tecnologia da carne associada à segurança alimentar.

\section{Material e métodos}

\section{Animais e coleta de amostras}

Foram utilizados 23 animais da raça Nelore (Bos indicus), sendo 15 provenientes de animais submetidos ao sistema de confinamento de três diferentes fazendas certificadas e relacionadas com grupos de Melhoramento Animal nas regiões de Palmeiras de GoiásGO, Campo Grande-MS e Bataguassu-MS, e oito animais de produção orgânica de manejo comercial da Região Sudeste, com selo de certificação exigido pela legislação. Após o abate em frigorífico comercial no ano de 2013, foram coletadas duas amostras/ bifes com espessura de uma polegada $(2,54 \mathrm{~cm})$ da meia carcaça esquerda entre $12^{\mathrm{a}}-13^{\mathrm{a}}$ costelas, devidamente embaladas a vácuo e imediatamente levadas ao freezer, para 
realização de análises laboratoriais no Laboratório de Ciência da Carne do Departamento de Melhoramento e Nutrição Animal (FMVZ-UNESP), em Botucatu-SP.

Força de cisalhamento (FC) e perdas totais

Para a determinação da força de cisalhamento, foi utilizado o equipamento SALTER Warner-Bratzler Shear Force mecânico, com capacidade de $25 \mathrm{~kg}$ e velocidade de seccionamento de $20 \mathrm{~cm} /$ minuto. Para a realização do ensaio, foi adotado o procedimento padronizado e proposto por Wheeler et al., ${ }^{12}$ segundo o qual as amostras foram assadas até atingirem temperatura interna de $71^{\circ} \mathrm{C}$. O shearing foi realizado em cilindros de meia polegada retirada da região central da amostra em sentido longitudinal às fibras musculares. Foram feitas oito medidas por amostra, a fim de se obter maior precisão nos resultados, que foram expressos em quilogramas $(\mathrm{Kg})$.

Durante o cozimento das amostras para análise da força de cisalhamento, foram coletados os dados necessários para cálculo dos valores de perdas totais (evaporação e gotejamento).

\section{Coloração instrumental da carne}

A determinação da coloração da carne foi realizada nas amostras utilizando colorímetro KONICA MINOLTA - CR 400 (Minolta Co. Ltd.), segundo metodologia proposta por Renerre, ${ }^{13}$ na qual o equipamento foi calibrado para um padrão branco no sistema CIE $L^{*} a^{*} b^{*}$ e adotadas as medidas absolutas das coordenadas de luminosidade $\left(L^{*}\right)$, coloração vermelha $\left(a^{*}\right)$ e coloração amarela $\left(b^{*}\right)$.

Área de olho de lombo (AOL), espessura de gordura subcutânea (EGS) e índice de marmorização (IM)

Para determinação da área de olho de lombo (AOL), foi utilizado o método do quadrante de pontos expresso em $\mathrm{cm}^{2},{ }^{14}$ bem como a espessura de gordura subcutânea (EGS), medida com paquímetro e apresentada em milímetros (mm). Na análise do IM, foi utilizada escala de graduação visual adaptada no Laboratório de Certificação da Carne (LCC) aos padrões de marmorização comumente encontrados no rebanho nacional. 


\section{Composição centesimal}

A composição química bruta foi realizada de acordo com técnicas indicadas pela Association of Analytical Communities (AOAC). ${ }^{15}$ Para o teor de umidade, foram utilizadas $10 \mathrm{~g}$ de cada amostra, submetidas a 105ํㅡ em estufa por no mínimo 12 horas e resfriadas em dessecadores por no mínimo duas horas. A matéria seca obtida de cada amostra foi incinerada em mufla à temperatura de 550-600 , para obtenção do teor de cinzas.

\section{Lipídeos totais (LT)}

A quantificação de lipídeos totais seguiu a metodologia descrita por Bligh \& Dyer, ${ }^{16}$ utilizando $3 \mathrm{~g}$ de carne crua e moída, $10 \mathrm{ml}$ de clorofórmio, $20 \mathrm{ml}$ de metanol e $8 \mathrm{ml}$ de água destilada. Após homogeneização das amostras, estas foram colocadas em mesa agitadora horizontal por 30 minutos.

Em seguida, foram adicionados $10 \mathrm{ml}$ de clorofórmio e $10 \mathrm{ml}$ de solução aquosa de sulfato de sódio $1,5 \%$, centrifugados a $1.000 \mathrm{Xg}$, descartando-se o sobrenadante, sendo o restante filtrado em papel filtro. Foram medidos $5 \mathrm{ml}$ do filtrado e transferidos para becker de $50 \mathrm{ml}$ previamente pesado, colocado em estufa a $110^{\circ} \mathrm{C}$ até evaporação total do solvente; depois foi resfriado em dessecador $(\mathrm{O} / \mathrm{N})$ e pesado.

\section{Índice de fragmentação miofibrilar (MFI)}

A determinação do índice de fragmentação miofibrilar (MFI) foi realizada conforme a metodologia descrita por Culler et al. ${ }^{17}$ e adaptada no Laboratório Ciência da Carne no Departamento Melhoramento e Nutrição Animal (FMVZ-UNESP) em Botucatu-SP.

Foram utilizados $3 \mathrm{~g}$ do músculo homogeneizados em Ultra-turrax a $18.000 \mathrm{rpm}$ em $30 \mathrm{ml}$ de tampão (TMFI) a ${ }^{\circ} \mathrm{C}$ e as amostras centrifugadas a $1.000 \mathrm{Xg}$ por 15 minutos a $2^{\circ} \mathrm{C}$, sendo o sobrenadante descartado. Esse procedimento foi repetido duas vezes. $\mathrm{O}$ pellet foi então ressuspendido em $15 \mathrm{ml}$ de TMFI a $2^{\circ} \mathrm{C}$ e filtrado. Foi feita a quantificação de proteínas miofibrilares totais pelo método do Macro Biureto. ${ }^{18}$ Para a determinação do MFI, as amostras foram preparadas com o TMFI para um volume final de $8 \mathrm{ml}$ e concentração de proteína $0,5 \mathrm{mg} / \mathrm{ml}$ e então foi feita a leitura em absorbância no comprimento de onda de $540 \mathrm{~nm}$ em espectrofotômetro. 


\section{Delineamento experimental e análise estatística}

As médias das oito medidas de força de cisalhamento (FC) foram analisadas segundo modelo de análise de variância simples, incluindo apenas o efeito de tratamento e o erro. O mesmo modelo foi utilizado para todas as medidas tomadas apenas uma vez nas amostras (IM, perdas totais, AOL e EGS). As análises das demais variáveis, que foram medidas diversas vezes em cada amostra do animal (MFI, coloração, LT, umidade e centesimal), foram realizadas seguindo um modelo de delineamento em parcelas subdivididas, em que cada animal é uma parcela e as medidas tomadas ao longo do tempo, as subdivisões da parcela. O modelo de análise para estas características foi:

$Y_{i j k}=\mathrm{u}+\mathrm{T}_{\mathrm{i}}+\mathrm{a}_{\mathrm{ij}}+\mathrm{M}_{\mathrm{k}}+\mathrm{I}_{\mathrm{ik}}+\mathrm{e}_{\mathrm{ijk}}$

Onde:

$Y_{i j k}=$ valor observado da característica (MFI, coloração, LT, centesimal e umidade) tomadas na amostra do animal j, pertencente ao tratamento i, no tempo k.

$\mathrm{u}=$ média geral;

$\mathrm{T}_{\mathrm{i}}=$ Efeito do tratamento $\mathrm{i}(\mathrm{i}=1,2)$;

$\mathrm{a}_{\mathrm{ij}}=$ Efeito do animal $\mathrm{j}(\mathrm{j}=1, . .12)$; dentro do tratamento $\mathrm{i}$;

$\mathrm{Mk}=$ Efeito do tempo $\mathrm{k}$ em que foi tomada a medida $(\mathrm{k}=1,2$ ou $\mathrm{k}=1, \ldots 5$, dependendo da variável analisada);

$\mathrm{I}_{\mathrm{ik}}=$ efeito da interação entre o tempo de medida e o tratamento.

$\mathrm{e}_{\mathrm{ijk}}=$ erro aleatório associado a cada observação em particular.

As médias foram comparadas utilizando-se o teste de Tukey. As análises pelo modelo simples foram realizadas utilizando-se o PROC GLM e as outras análises utilizando-se o PROC MIXED, ambos do sistema SAS. ${ }^{19}$

\section{RESULTADOS E DISCUSSÃO}

De acordo com Figueiredo \& Soares, ${ }^{4}$ foi observado que nas regiões Centro-Oeste, Norte e Nordeste, é pequena a comercialização de produtos orgânicos, representando apenas $6 \%$ dos canais de venda, o que pode estar relacionado à necessidade de adquirir as amostras da Região Sudeste. A procedência comercial das amostras orgânicas obtidas neste trabalho tornou-se mais viável, devido à insuficiência de fazendas ou frigoríficos com selo de certificação orgânica no Brasil, requisito valorizado pelos consumidores. ${ }^{20}$ 
Além da certificação da carne, a coloração é a principal característica sensorial observada pelo consumidor no ato da compra. A coloração do corte cárneo pode ser classificada, de acordo com Abularach et al., ${ }^{21}$ em: carnes claras $\left(\mathrm{L}^{*}>38,51\right)$, com intensidade média de vermelho (baixa $\mathrm{a}^{*}<14,83$; alta $\mathrm{a}^{*}>29,27$ ) e alta tonalidade de amarelo $\left(b^{*}>8,28\right)$. Sendo assim, podemos observar, na tabela 1 , que as amostras de procedência orgânica apresentaram maior luminosidade, intensidade de vermelho e amarelo, comparando-se com as de produção convencional.

Tabela 1. Valores da estatística descritiva para característica de coloração instrumental ( $L^{*}$, $\mathrm{a}^{*}$ e b*) mensurada em animais Nelore (Bos indicus), submetidos a diferentes sistemas de produção. Botucatu-SP, 2013.

\begin{tabular}{ccc}
\hline Variáveis & Convencional & Orgânica \\
\hline Luminosidade $\left(\mathrm{L}^{*}\right)$ & $31,8 \pm 2,93 \mathrm{a}$ & $41,3 \pm 0,76 \mathrm{~b}$ \\
Vermelho $\left(\mathrm{a}^{*}\right)$ & $12,3 \pm 2,34 \mathrm{a}$ & $21,4 \pm 1,97 \mathrm{~b}$ \\
Amarelo $\left(\mathrm{b}^{*}\right)$ & $5,4 \pm 1,57 \mathrm{a}$ & $10,6 \pm 0,41 \mathrm{~b}$ \\
\hline
\end{tabular}

a,b Médias seguidas por letras minúsculas diferentes, na mesma linha, diferem entre si $(\mathrm{p}<0,05)$ pelo teste Tukey.

A tonalidade de vermelho (a*) observada no presente estudo para as amostras dos animais provenientes do sistema orgânico apresentaram média superior aos animais oriundos do sistema convencional. Este fato pode ser justificado pelas diferenças encontradas nos distintos princípios de manejo e produção. Sañudo et al. ${ }^{22}$ relatam que animais produzidos no pasto podem apresentar maior quantidade de mioglobina e maior número de fibras vermelhas no músculo, devido às atividades e ao esforço físico necessário para alimentação dos animais utilizando o pastejo. Entretanto, segundo Felício, ${ }^{23}$ a elevada concentração de mioglobina relaciona-se com o abate tardio dos animais, que apresentam maior maturidade.

A coloração da carne pode estar relacionada ao estado físico da carne, principalmente ao pH de sua superfície e outros fatores, como hidratação e estado das proteínas musculares. O alto teor de amarelo na gordura da carne bovina é geralmente classificado pelos consumidores como animais velhos no entanto, animais terminados em pastagens, como em nosso estudo, geralmente apresentam elevados teores de amarelo, os quais podem ser correlacionados com altas quantidades de $\beta$-caroteno, o que pode ser benéfico para a saúde humana. ${ }^{24}$ 
Dentre as análises objetivas de maciez para a carne bovina, os resultados de força de cisalhamento foram diferentes nas amostras bovinas de origem orgânica e convencional (tabela 2). Os animais orgânicos apresentaram média de FG inferior aos animais convencionais. Segundo Oliveira, ${ }^{25}$ o valor de FC aceitável para maciez é inferior a 4,5kg. De acordo com Koohmaraie, ${ }^{26}$ carnes com valores de força de cisalhamento (FC) abaixo de $5,5 \mathrm{~kg}$ podem ser consideradas potencialmente macias após o cozimento; e valores médios de $\mathrm{FC}$ abaixo de $3,5 \mathrm{~kg}$ podem demonstrar a capacidade de todos os indivíduos de produzir carne com valores de $\mathrm{FC}$ abaixo de $5,5 \mathrm{~kg}^{27}$ - ou seja, rebanhos com carne $100 \%$ macia, como os encontrados no presente ensaio.

Tabela 2. Médias para as análises físicas do músculo Longissimus thoracis (12ª̂-13a costelas) de animais Nelore submetidos aos sistemas de produção convencional e orgânica. Botucatu-SP, 2013.

\begin{tabular}{ccc}
\hline Variáveis & Convencional & Orgânica \\
\hline AOL $(\mathrm{cm} 2)$ & $66 \pm 5,64 \mathrm{a}$ & $84 \pm 1,41 \mathrm{~b}$ \\
EGS $(\mathrm{mm})$ & $4,6 \pm 1,54 \mathrm{a}$ & $6 \pm 0,10 \mathrm{~b}$ \\
IM & $2,6 \pm 0,3$ & $2,2 \pm 0,07$ \\
FC $(\mathrm{kg})$ & $5,4 \pm 1,12 \mathrm{a}$ & $2,2 \pm 0,15 \mathrm{~b}$ \\
PT $(\%)$ & $24,2 \pm 3,96$ & $26,0 \pm 1,01$ \\
\hline
\end{tabular}

$\overline{\mathrm{AOL}}=$ área de olho de lombo, $\mathrm{EGS}=$ espessura de gordura subcutânea, $\mathrm{IM}=$ índice de marmorização, $\mathrm{FC}=$ força de cisalhamento, $\mathrm{PT}=$ perdas totais.

a,b Médias seguidas por letras minúsculas diferentes, na mesma linha, diferem entre si $(\mathrm{p}<0,05)$ pelo teste Tukey.

Vários estudos relatam que a carne bovina de animais da raça Nelore apresentam maior FC, quando comparados a mestiços terminados em confinamento, ${ }^{28,29}$ bem como no pasto. ${ }^{30}$ Uma possível explicação para os maiores valores encontrados de FC em animais Nelore pode ser parcialmente atribuída à maior atividade/concentração do inibidor enzimático calpastatina, proteína reguladora da atividade enzimática das calpaínas, o que levaria à diminuição da proteólise miofibrilar, com consequente diminuição na maciez da carne. ${ }^{28}$

$\mathrm{Na}$ avaliação de parâmetros de desenvolvimento animal observados, o valor encontrado para a área de olho de lombo (AOL) foi superior para os animais provenientes de origem orgânica em relação aos convencionais. Esta característica é avaliada no músculo Longissimus thoracis e apresenta boa relação com a quantidade de músculos 
presentes na carcaça. Desta forma, contribui para a predição do rendimento de cortes cárneos, mostrando alta correlação com a quantidade de tecido comestível. ${ }^{11,29,31}$

A discrepância de valores da AOL observada nos distintos grupos pode ser explicada através do desenvolvimento do animal, pois ocorrem mudanças na composição da carcaça em relação à quantidade de músculo, gordura e ossos. Essa deposição pode ser influenciada por fatores genéticos e ambientais. Os tecidos nervoso e ósseo têm um desenvolvimento mais precoce, enquanto o muscular é intermediário e o adiposo geralmente desenvolve-se mais tardiamente. A distribuição do tecido adiposo possui importância direta na qualidade da carcaça, protegendo o músculo do encurtamento pelo frio (cold shortening), caracterizado pela diminuição drástica do sarcômero muscular antes do rigor mortis. ${ }^{32}$

Segundo Alves \& Mancio, ${ }^{10}$ a influência da alimentação na maciez da carne está associada principalmente com o grau de acabamento (espessura de gordura subcutânea) e com o teor de gordura intramuscular na carcaça. As carcaças de animais bem acabados, com cobertura de gordura adequada e bom grau de marmorização, tendem a apresentar carne mais macia quando avaliadas por técnicas laboratoriais ou painéis de degustação.

Trabalhando com animais Nelore com aproximadamente 24-30 meses de idade, Hadlich et al. ${ }^{33}$ observaram poucas variações individuais nas características de carcaça e de qualidade de carne. Os autores atribuíram a igualdade nas características analisadas ao sistema de acabamento dos animais em confinamento, que tende a padronizar as carcaças e seus respectivos produtos cárneos.

No presente estudo, pôde-se observar diferença significativa entre os grupos avaliados para EGS, em que os animais convencionais apresentaram adequado grau de acabamento, talvez devido à utilização do sistema de confinamento, apresentando assim menor deposição de gordura subcutânea. O tecido adiposo tem causado desaprovação em relação ao surgimento de doenças cardiovasculares, arteriosclerose, colesterol, dentre outras.

Já para Aferri et al., ${ }^{34}$ e Prado et al., ${ }^{35}$ os animais confinados e as alternativas de implantação de diferentes tipos de dietas não apresentam relação significativa com características de carcaça, área de olho de lombo e espessura de gordura, dentre outras características relevantes no momento de análise da carne, demonstrando que a alimentação a pasto pode ser fonte eficaz e nutritiva. ${ }^{7}$

Para o consumidor moderno, o sabor e o valor nutricional são dois importantes atributos da qualidade da carne. A tendência é se concentrar na produção de carne magra, com um mínimo de excesso de gordura visível; em contrapartida, a gordura na subcutânea e intramuscular da carne contribui para a qualidade desta. ${ }^{36,37}$ 
Os valores encontrados na tabela 3 para os teores de lipídeos totais também se destacaram para os orgânicos, demonstrando possível correlação positiva entre teores de lipídeos e maciez na carne bovina orgânica, uma vez que a quantidade de gordura está relacionada com a qualidade da carne. ${ }^{11}$ Em contrapartida, em estudos realizados com gado a pasto, estes geralmente são abatidos com menores pesos, produzindo carcaças com menores porcentagens lipídicas e, consequentemente, formando carnes mais duras. ${ }^{38}$

Tabela 3. Médias para as análises químicas do músculo Longissimus thoracis de animais Nelore submetidos aos sistemas de produção convencional e orgânica. Botucatu-SP, 2013.

\begin{tabular}{ccc}
\hline Variáveis & Convencional & Orgânica \\
\hline LT $(\%)$ & $0,57 \pm 0,24 \mathrm{a}$ & $1,5 \pm 0,79 \mathrm{~b}$ \\
MFI & $46,7 \pm 18,01 \mathrm{a}$ & $21,3 \pm 1,87 \mathrm{~b}$ \\
Umidade $(\%)$ & $77,3 \pm 7,11 \mathrm{a}$ & $98,6 \pm 0,21 \mathrm{~b}$ \\
Cinzas & $1,1 \pm 1,23$ & $1,3 \pm 0,17$ \\
\hline
\end{tabular}

LT = lipídeos totais, MFI = índice de fragmentação miofibrilar.

a,b Médias seguidas por letras minúsculas diferentes, na mesma linha, diferem entre si $(\mathrm{p}<0,05)$ pelo teste Tukey.

O aumento da taxa de lipídios no músculo Longissimus thoracis em animais da raça Nelore indica maior deposição de gordura de marmorização; ${ }^{39}$ entretanto, esses animais apresentam pouca síntese lipídica no tecido muscular e, consequentemente, menor porcentagem de lipídeos totais na carne. ${ }^{27}$ Apesar da diferença significativa de LT entre os diferentes grupos, ambos apresentaram baixa deposição de gordura intramuscular, como é comumente observado em animais Bos indicus.

O valor médio de índice de marmorização foi classificado como escasso, e discordou dos valores de LT, o que pode ser explicado pelo fato de o IM ser uma análise de avaliação subjetiva observada na carne, podendo confiar na análise de LT devido a sua objetividade.

A importância da proteólise postmortem também foi citada por autores que relataram a estreita ligação existente entre maciez da carne e o índice de fragmentação miofibrilar. ${ }^{17}$ Neste sentido, os valores encontrados para o MFI foram maiores para os animais confinados em relação aos orgânicos (tabela 3), contradizendo os valores observados de FC. Estas são medidas inversamente proporcionais, onde a menor FC está diretamente 
relacionada à maior proteólise miofibrilar. Os resultados obtidos neste estudo demonstram haver variações numéricas significativas entre os animais dos tratamentos experimentais.

Não houve diferenças notáveis entre os teores de cinzas totais entre os grupos analisados, mas houve pequenas diferenças nos teores de umidade, sendo que os animais provenientes de sistema orgânico obtiveram maiores valores de porcentagem de umidade, em comparação aos confinados, o que pode ser relacionado com a suculência da carne bovina.

Em estudo realizado por Abularach et al., ${ }^{21}$ foram relatados valores de umidade e lipídeos de 75,65\% e 1,71\%, respectivamente, para tourinhos Nelore de 24 meses de idade, valores diferentes dos encontrados neste estudo e podem estar relacionados com a idade do abate do animal. Silva et al. ${ }^{40}$ verificaram valores para o músculo Longissimus dorsi de novilhas Eurozebu variando de 74,3 a $75,2 \%$, e Vaz et al. ${ }^{41}$ obtiveram maior valor de umidade na carne de animais inteiros em relação aos castrados Charolês $\mathrm{x}$ Nelore (71,9 versus 70,8\%). Já Rodrigues et al. ${ }^{42}$ e Hautrive et al. ${ }^{43}$ observaram valores de umidade próximos a $73,5 \%$. E os valores de perdas totais se aproximaram dos encontrados por Felício et al., ${ }^{44}$ de $25,18 \%$ para carne de novilhos Nelore. Durante o cozimento da carne, a perda de água altera o rendimento do produto, afetando a palatabilidade e influenciando sua aceitabilidade. ${ }^{45,46}$ Ainda que os cortes analisados tenham apresentado valores satisfatórios e pesquisas sobre alimentos orgânicos estejam em constante desenvolvimento, é notável que fatores como solo, clima, genética e períodos pós-colheita ou abate possuem influência direta sobre a composição dos alimentos, ${ }^{47} \mathrm{O}$ que enfatiza as diferenças químicas encontradas neste estudo.

Também é visível a inconsistência da maciez em bovinos Nelore em relação a outros tipos de raça comumente encontrados no Brasil e em outros países. Exige-se, assim, aprimoramento nas áreas de melhoramento animal nos centros de pesquisa da carne, juntamente com tecnologias de preservação e a sustentabilidade das áreas de produção no pasto. ${ }^{7,48}$

A carne bovina é um alimento importante inserido no padrão alimentar da população em aspectos nutricionais e no agronegócio. É uma das variedades de carne mais consumidas nos Estados Unidos, Brasil, Japão e China, com destaque para o Brasil, segundo maior exportador. Portanto, as possíveis relaçóes entre a qualidade e a composição nutricional da carne foram avaliadas através dos dados obtidos nas análises físico-químicas dos cortes cárneos, bem como suas possíveis relações com a composição nutricional e de qualidade da carne dos diferentes grupos de animais submetidos aos distintos sistemas de produção. 


\section{Conclusões}

Animais da raça Nelore (Bos indicus) demonstram grande habilidade em produzir carne, fato denotado no grupo de animais convencionais e orgânicos, através dos valores observados de AOL, bem como na deposição de gordura subcutânea (EGS). Entretanto, de maneira geral, pela menor síntese lipídica e altos valores nas perdas por cozimento, apresentam um produto de menor valor agregado quanto às características de qualidade de carne.

A carne bovina proveniente de sistema orgânico apresentou diferenças significativas, envolvendo aspectos com sua qualidade em relação à carne bovina habitualmente consumida pela população. Sendo assim, a realização de mais estudos envolvendo esse tipo de alimento e as tecnologias envolvidas com o processo de produção e sustentabilidade é de grande importância dentro dos elos da cadeia produtiva e para o mercado consumidor.

\section{Agradecimentos}

Agradecemos ao Programa Institucional de Bolsas de Iniciação Científica (PIBIC) e à Fundação de Amparo à Pesquisa do Estado de São Paulo (FAPESP), pelo apoio financeiro.

\section{Referências}

Mooz ED, Silva MV. Organic food in the national and international scenarios. Nutrire: Rev. Soc.

Bras. Alim. Nutr. 2014; 39(1):99-112.

1. Instituto Brasileiro de Geografia e Estatística. Censo Agropecuário 2006 [Internet]. Rio de Janeiro: IBGE. [acesso em dez. 2013]. Disponível em: http://saladeimprensa.ibge.gov.br

2. Food and Agriculture Organization of the United Nations [Internet]. [acesso em: fev. 2014]. Disponível em: https://www.fao.org.br/

3. Figueiredo EAP, Soares JPG. Sistemas orgânicos de produção animal: dimensões técnicas e econômicas. Anais da 49 $9^{a}$ Reunião Anual da Sociedade Brasileira de Zootecnia: A produção animal no mundo em transformação; 23-26 jul. 2012; Brasília.

4. Stolze M, Lampkin N. Policy for organic farming: rationale and concepts. Food Policy 2009; 34:237244.

5. Robbins K, Jensen J, Ryan KJ, Homco-Ryan C, McKeith FK, Brewer MS. Consumer attitudes towards beef and acceptability of enhanced beef. Meat Science 2003; 65(2):721-729.

6. Lobato JFP, Freitas AK, Devincenzi T, Cardoso LL, Tarouco JU, Vieira RM, et al. Brazilian beef produced on pastures: Sustainable and healthy. Meat Science 2014 98(3):336-345. 
7. Associação Brasileira das Indústrias Exportadoras de Carnes [Internet]. São Paulo. [acesso jul. 2014]. Disponível em: http://www.abiec.com.br

8. Highfill CM, Esquivel-Font O, Dikeman ME, Kropf DH. Tenderness profiles of ten muscles from F1 Bos indicus x Bos taurus and Bos Taurus cattle cooked as steaks and roasts. Meat Science 2012; 90(4):881-886.

9. Alves DD, Mancio AB. Maciez da carne bovina: uma revisão. Revista FZVA 2007; 14(1):193-216.

10. Costa EC, Restle J, Brondani IL, Perottoni J, Faturi C, Menezes LFG. Composição física da carcaça, qualidade da carne e conteúdo de colesterol no músculo Longissimus dorsi de Novilhos Red Angus Superprecoces, Terminados em confinamento e abatidos com diferentes pesos. R. Bras. Zootec. 2002; 31(1) 417-428.

11. Wheeler TL, Koohmaraie M, Shackelford SD. Standardized Warner- Bratzler Shear Force procedures for meat tenderness measurement. Proc. Recip. Meat Conf. 1995; 50:68-77.

12. Renerre M. La coleur de la viande et sa mesure. Bulletin Technique, C.R.V.Z., Theix, I.N.R.A. 1982; 47:47-54.

13. United States Standards for Grades of Feeder Cattle. Agricultural marketing service. Washington, D.C.: Livestock and Seed Program, USDA; 2000.

14. The Association of Analytical Communities. Official methods of analysis. $15^{a}$ ed. Arlington: AOAC; 1995.

15. Bling EG, Dyer WJ. A rapid method of total lipid extraction and purification. Can. J. Biochem. Physiol. 1959; 37(8):911- 917.

16. Culler RD, Parrish JR FC, Smith GC, Cross HR. Relationship of myofibril fragmentation index to certain chemical, physical and sensory characteristics of bovine longissimus muscle. Journal of Food Science 1978; 43(4):1177-1180.

17. Gornall AG, Bardawill CJ, David MM. Determination of serum proteins by means of biuret reaction. J. Biol. Chem 1949; 177(2):751-766.

18. Statistical Analysis System Institute. SAS user's guide: statistics. Cary: Statistical Analysis System Institute; 2011.

19. Velho JP, Barcellos JOJ, Lengler L, Elias SA, Oliveira, TE. Disposição dos consumidores portoalegrenses à compra de carne bovina com certificação. R. Bras. Zootec. 2009; 38(2):399-404.

20. Abularach MLS, Rocha CE, Felício PE. Características de qualidade do contrafilé (m. L. dorsi) de touros jovens da raça Nelore. Ciência Tecnologia de Alimentos 1998; 18(2):205-210.

21. Sañudo C, Santolaria MP, Maria GA, Osório M, Sierra I. Influence of carcass weight on instrumental and sensory lamb meat quality in intensive production systems. Meat. Science 1996; 42(2):195-202.

22. Felício PE. Qualidade da carne bovina: características físicas e organolépticas. In: Anais da $36^{a}$ Reunião Anual da Sociedade Brasileira de Zootecnia; 1999. Porto Alegre. Brasília: Sociedade Brasileira de Zootecnia; 1999. p. 89-97.

23. Rossato LV, Bressan MC, Rodrigues EC, Gama LT, Bessa RJB, Alves SPA. Parâmetros físico-químicos e perfil de ácidos graxos da carne de bovinos Angus e Nelore terminados em pastagem. R. Bras. Zootec. 2010; 39(5):1127-1134. 
24. Oliveira AL. Maciez da carne bovina. Cadernos Técnicos de Veterinária e Zootecnia 2000; 33:7-18.

25. Koohmaraie M. Muscle proteinases and meat aging. Meat Science 1994; 36:93-104.

26. Chardulo LAL, Silveira AC, Vianello F. Analytical aspects for tropical meat quality assessments. In: Lima GPP; Vianello F. Food Quality, Safety and Technology. Springer-Verlag Wien; 2013. p. 53-62.

27. Lage JF, Paulino PV, Filho SC, Souza EJ, Duarte MS, Benedeti PD, et al. Influence of genetic type and level of concentrate in the finishing diet on carcass and meat quality traits in beef heifers. Meat Science 2012; 90(3):770-774.

28. Pereira PMRC, Pinto MF, Abreu UGP, Lara JAF. Características de carcaça e qualidade de carne de novilhos superprecoces de três grupos genéticos. Pesq. Agropec. Bras. 2009; 44(11):1520-1527.

29. Heinemann RJB, Pinto MF, Romanelli PF. Fatores que influenciam a textura da carne de novilhos Nelore e cruzados Limousin x Nelore. Pesq. Agropec. Bras. 2003; 38(8):963-971.

30. Ribeiro EL, Hernandez JA, Zanella EL, Shimokomaki M, Prudêncio-Ferreira, SH, Youssef E, et al. Growth and carcass characteristics of pasture fed LHRH immunocastrated, castrated and intact Bosindicus bulls. Meat Science 2004; 68(2):285-290.

31. Giusti J. Expressão de genes relacionados à qualidade da carne do músculo Longissimus dorsi em Nelore (Bos indicus) e canchim (5/8 Bos taurus x 3/8 Bos indicus) [Tese]. Jaboticabal, SP: Universidade Estadual Paulista, Faculdade de Ciências Agrárias e Veterinárias; 2011. p. 74.

32. Hadlich JC, Morales DC, Silveira AC, Oliveira HN, Chardulo LAL. Efeito do colágeno na maciez da carne de bovinos de distintos grupos genéticos. Acta Sci. Anim. Sci. 2006; 28(1):57-62.

33. Aferri G, Leme PR, Silva SL, Putrino SM, Pereira ASC. Desempenho e características de carcaça de novilhos alimentados com dietas contendo diferentes fontes de lipídios. R. Bras. Zootec 2005; 34(5):1651-1658.

34. Prado IN, Pinheiro AD, Alcalde CR, Zeoula LM, Nascimento WG, Souza NE. Níveis de substituição do milho pela polpa de Citrus Peletizada sobre o desempenho e características de carcaças de bovinos mestiços confinados. Rev. Bras. Zootec. 2000; 29(6): 2135-2141.

35. Wood JD. Consequences for meat quality of reducing carcass fatness. In: Wood JD, Fisher AV, editors. Reducing fat in meat animals. England: Elsevier Science Publishers; 1990. p. 344-389.

36. Webb EC. Manipulating beef quality through feeding. South African Animal Science 2006; 7:5-15.

37. Bridi AM, Constantino C. Qualidade e avaliação de carcaças e carnes bovinas ]Internet]. GPAC. [acesso em jul. 2014] Disponível em: http://www.uel.br/grupo-pesquisa/gpac/pages/arquivos/ Qualidade $\% 20 \mathrm{e} \% 20$ Avaliacao\%20de $\% 20$ Carcacas $\% 20 \mathrm{e} \% 20$ Carnes $\% 20$ Bovinas.pdf

38. Fortes MRS, Curi RA, Chardulo LAL, Silveira AC, Assumpção MEOD, Visintin JA, et al. Bovine gene polymorphisms related to fat deposition and meat tenderness. Genetics and Molecular Biology 2009; 32(1):75-82.

39. Silva RG, Prado IN, Matsushita M, Souza NE. Dietary effects on muscle fatty acid composition of finished heifers. Pesq. Agropec. Bras. 2002; 37(1):95-101. 
40. Vaz FN, Restle J, Feijó GLD, Restle J, Brondani IL, Rosa JRP, et al. Qualidade e composição química da carne de bovinos de corte inteiros ou castrados de diferentes grupos genéticos Charolês x Nelore. Rev. Bras. Zootec. 2001; 30(2):518-525.

41. Rodrigues VC, Andrade IF. Características físico-químicas da carne de bubalinos e de bovinos castrados e inteiros. Rev. Bras. Zootec. 2004; 33(6):1839-1849.

42. Hautrive TP, Marques AC, Kubota EH. Avaliação da composição centesimal, colesterol e perfil de ácidos graxos de cortes cárneos comerciais de avestruz, suíno, bovino e frango. Alimento e Nutrição 2012; 23(2):327-334.

43. Felício PE. Carcass composition and quality traits of zebu steers slaughtered in the state of São Paulo Brazil [Tese]. Kansas: Kansas State University; 1981.

44. Kondjoyan A, Oillic S, Portanguen S, Gros JB. Combined heat transfer and kinetics model to predict cooking loss during heat treatment of beef meat. Meat Science 2013; 95(2):336-344.

45. Modzelewska-Kapitula M, Dabrowska E, Jankowska B, Kwialkowska A, Cierach M. The effect of muscle, cooking method and final internal temperature on quality parameters of beef roast. Meat Science 2012; 91(2):195-202.

46. Ferraz APCR, Malheiros JM, Cintra RMG. A produção, o consumo e a composição química dos alimentos orgânicos. Rev. Simbio-logias 2013; 6(9):31-42.

47. Elzo MA, Johnson DD, Wasdin JG, Driver JD. Carcass and meat palatability breed differences and heterosis effects in an Angus-Brahman multibreed population. Meat science 2012; 90(1): 87-92. 
